\title{
BANCO DE DADOS VARSUL: A RELEVÂNCIA DE SUAS CARACTERÍSTICAS E A ABRANGÊNCIA DE SEUS RESULTADOS
}

\author{
Gisela COLLISCHONN* \\ Valéria de Oliveira MONARETTO**
}

- RESUMO: O Banco de Dados VARSUL (Variação Linguística Urbana do Sul do País) reúne dados de fala de localidades sócio e culturalmente significativas de três Estados do Sul do Brasil. Este artigo apresenta uma reflexão sobre a utilização dos dados de coletâneas de entrevistas levantadas segundo metodologia laboviana, tanto na área de variação linguística quanto em diversas outras áreas de pesquisas, especialmente no que diz respeito a pesquisas fonológicas. A importância e as vantagens obtidas por análises em corpora de língua falada espontânea são abordadas. Discutimos também a possibilidade que levantamentos feitos em moldes de entrevistas sociolinguísticas oferecem para a interface com outras áreas de pesquisa. Algumas características da constituição do Banco VARSUL são apresentadas, tais como a metodologia de obtenção de dados, critérios de seleção dos informantes, modelo de transcrição, facilidades de buscas, entre outras. Ao final, apresentamos um breve levantamento de pesquisas realizadas com esses dados e que tiveram, como objeto de análise, fenômenos fonético-fonológicos variáveis a fim de ilustrar a abrangência de fenômenos já estudados e de mostrar a possibilidade de generalização de resultados.

- PALAVRAS-CHAVE:VARSUL. Banco de Dados de Fala. Variação Fonológica.

\section{Introdução}

A documentação da língua falada é fundamental para que os estudiosos da linguagem tenham onde buscar comprovação empírica para suas hipóteses e teorias. Nesse sentido, parece-nos que um banco de dados de fala tenha relevância implícita, independentemente da metodologia de coleta e de organização dos dados. Entretanto, dado que as abordagens em termos de coleta de dados e de foco da investigação linguística vão se aperfeiçoando e se modificando continuamente, cremos que cabe a discussão sobre a questão da relevância de um banco, como o VARSUL (Variação Linguística Urbana do Sul do País).

* UFRGS - Universidade Federal do Rio Grande do Sul. Instituto de Letras - Departamento de Línguas Clássicas e Vernáculas. Porto Alegre - Rio Grande do Sul - Brasil. 91350-300 - giselac@via-rs.net

** UFRGS - Universidade Federal do Rio Grande do Sul. Instituto de Letras - Departamento de Lingüística, Filologia e Teoria Literária. Porto Alegre - Rio Grande do Sul - Brasil. 91350-300 - monar@terra.com.br 
O Banco VARSUL é fruto de cuidadosa coleta de dados de língua falada que compreende amostras representativas de cidades dos três estados do Sul: Paraná, Santa Catarina e Rio Grande do Sul. Na formação do ProjetoVARSUL, definiu-se que quatro cidades de cada estado fariam parte do corpus. Cada cidade é representada por um conjunto de 24 entrevistas. Os indivíduos da amostra estão distribuídos por sexo, escolaridade e idade. Seguindo a metodologia laboviana, as entrevistas buscam ser representativas da linguagem falada (autêntica e natural, na medida do possível). Por isso, busca-se deixar o informante discorrer sobre diversos temas (em geral, sobre algum aspecto da história de vida do entrevistado), sem muita interferência do entrevistador, justamente para tentar minimizar a artificialidade da situação. Os dados de fala são gravados e posteriormente transcritos.

O VARSUL foi criado em uma época em que eram, no País, extremamente escassos registros de língua falada e estudos empíricos descritivos sobre variáveis linguísticas em geral. O projeto pioneiro nesse sentido foi o Projeto Censo, proposto em 1980 com o objetivo de se estudar a variação e mudança no Rio de Janeiro. Entre 1980 e 1984, foram coletadas entrevistas com informantes distribuídos por diferentes faixas etárias, níveis de escolaridade e sexo. Essa amostra foi ampliada ao longo dos anos, formando o acervo de dados do Programa de Estudos sobre os Usos da Língua (PEUL). O projeto PEUL tornou-se referência para os demais projetos de coleta de língua falada, como o VARSUL, VALPB e outros.

Na região Sul, especificamente, dados que atestassem o uso da língua falada, haviam sido coletados, pioneiramente, pelo Projeto Norma Urbana Culta (NURC), que buscou investigar a fala de indivíduos com curso superior nas cinco capitais mais populosas à época, no início da década de setenta, e que incluiu a cidade de Porto Alegre, no Rio Grande do Sul.

Ao fazer uma retomada da história dos estudos sociolinguísticos, Eckert (2012) identifica três ondas sucessivas. A primeira focava o estabelecimento de padrões de correlação entre variáveis linguísticas e as grandes categorias classe social, sexo, etnia e idade, consideradas significativas em qualquer comunidade linguística. A segunda, com o emprego dos métodos da etnografia, buscava explorar categorias mais locais e identificar as configurações que constituem as categorias mais amplas. Nestas duas primeiras ondas, a perspectiva principal era de que a variação seria reflexo das categorias sociais pré-estabelecidas. Na terceira onda, segundo Eckert (2010), o estudo da variação focaliza o significado social dos empregos das formas linguísticas e procura identificar as categorias que são construídas socialmente em uma determinada comunidade.

A constituição do Banco VARSUL está inserida na primeira onda, que Eckert (2012) chama de "era dos inquéritos". Levantamentos em grande escala, com base no modelo pioneiro de Labov (1966), foram sendo desenvolvidos para diversas línguas, envolvendo um grande número de informantes. Com isso, foi 
possível obter uma visão ampla da variação e dos padrões de distribuição social das variáveis. Entre as principais virtudes desses levantamentos estão a sua cobertura e replicabilidade. No entanto, essas vantagens vêm com o senão de que dependem do emprego de categorias sociais pré-determinadas, empregadas para classificar os informantes. Como resultado, não permitem uma visão mais detalhada dos papéis que os informantes de fato desempenham dentro do grupo.

A segunda onda utilizou métodos etnográficos para se aproximar das dinâmicas locais de variação e, por isso mesmo, concentrou-se em pequenas comunidades, por períodos relativamente longos de tempo. Em vez de pressupor que determinadas categorias sejam relevantes, os métodos buscam descobrir quais são as categorias localmente relevantes. Esta segunda onda tomou forma a partir das conclusões da onda anterior, isto é, a partir da constatação de que nem sempre as macrocategorias apresentavam o comportamento esperado a partir das supostas características sociais do fenômeno analisado.

Na terceira onda, inverte-se a abordagem. Em vez da perspectiva de variação como um reflexo do lugar social, assume-se a perspectiva da variação como um recurso para a construção de sentido social. Segundo Eckert (2012), a terceira onda nos afasta da perspectiva macrossociológica, olhando para a negociação momento a momento das relações de poder entre os falantes.

Neste artigo, em que reapresentamos aos leitores o Banco VARSUL, é importante - além de destacarmos resultados que já foram encontrados refletirmos a respeito do acesso ao Banco por uma comunidade mais ampla de pesquisadores e sobre a relevância que dados coletados no contexto de uma perspectiva sociolinguística caracteristicamente da primeira onda podem ter para outras perspectivas de investigação. Nas próximas duas seções, trazemos algumas reflexões nesse sentido, considerando o valor que pesquisas de corpora têm adquirido nos desenvolvimentos teóricos recentes e as vantagens de corpora de língua falada espontânea em comparação com a fala captada em condições de laboratório. Em seguida, passamos a apresentar a caracterização do Banco, explicitando os cuidados metodológicos que foram tomados para garantir uma coleta tão fidedigna quanto possível. Na última seção, apresentamos resultados já obtidos, no que se refere às pesquisas na área de variação fonológica.

\section{Por que corpora em larga-escala?}

Segundo Eckert (2012), nenhuma onda substitui a anterior, embora cada uma represente uma forma bastante diferente de se pensar sobre a variação e também uma prática metodológica e analítica distinta. Como destaca Eckert (2012), os amplos padrões demográficos de variação não deixaram de ser importantes. Corpora como o VARSUL, por se constituírem de amostras aleatoriamente 
estratificadas segundo padrões sociais pré-estabelecidos, têm valor por possibilitar o (re)conhecimento da distribuição de variáveis linguísticas de acordo com esses padrões. Dada a riqueza e abrangência das entrevistas coletadas, ainda há muito o que pesquisar em termos dessas correlações.

Também deve-se destacar que o estudo da variação ganhou novo impulso, deixando de ficar restrito à comunidade sociolinguística. No que concerne à relevância da variação em fonologia, por exemplo, há uma clara mudança em curso. Coeetze e Pater (2011), em recente capítulo sobre a variação em fonologia, na segunda edição do Handbook of Phonological Theory (GOLDSMITH; RIGGLE; YU, 2011), notam que, na primeira edição do Handbook, sequer havia um capítulo sobre variação, ao passo que, na atualidade, qualquer texto que tenha como proposta abranger a área de fonologia adequadamente e que pretenda dar uma perspectiva consequente do estado da arte na fonologia teórica não pode deixar de ter uma seção ou um capítulo dedicado à variação.

Ainda em Hinskens, Hout e Wetzels (2000, p.8-9) observavam o seguinte:

[...] nem todos os linguistas orientados mais teoricamente parecem estar suficientemente cônscios de que a variação é uma característica essencial da língua, tanto quanto um pré-requisito para a evolução linguística. [...] Os poucos linguistas teóricos que mostram sensibilidade para o problema da variação raramente têm idéias claras com relação ao lugar da variação linguística em seus modelos.

Essa realidade parece já ter mudado bastante. Há uma maior integração, que se deve, em parte, aos desenvolvimentos das teorias fonológicas, no sentido de incorporar um componente probabilístico, e, em parte, ao fato de que os trabalhos em variação cada vez mais buscam levar em consideração as análises elaboradas pela fonologia teórica na tentativa de entender as relações estruturais entre os fenômenos linguísticos.

Dados quantitativos lançam luz sobre muitas questões que não podem ser respondidas simplesmente pela intuição e permitem comparar estruturas hipotéticas com estruturas atestadas. Ou seja, estudos de corpora sociolinguísticos podem contribuir para uma sustentação mais sólida na realidade de análises de caráter mais teórico. Além disso, conforme nos alerta Durand (2009, p.39), baseando-se apenas na intuição, o linguista pode estar correndo o risco de formalizar seus pressupostos normativos sobre a língua. Por mais que a linguística moderna reconheça a prioridade da fala sobre a escrita e rejeite o prescritivismo, é muito fácil para o analista tornar-se refém de conceitos derivados de ortografia e do ensino escolar caso não se debruce com alguma regularidade sobre dados de língua falada. 
Finalmente, é de se destacar que corpora como o do Banco VARSUL permitem uma interface com outras áreas, tais como a pesquisa de corpus e a área de pesquisas geolinguísticas, como demonstram pesquisas como a de Brandão (2009), Mota (2009), Callou (2010), entre outros.

Kendall (2011) observa que é na pesquisa sociolinguística da primeira onda, e talvez também na da segunda onda, que estudos de linguística de corpus podem encontrar correspondência. Segundo o autor:

[...] it seems likely that continued technological advancements in the development, annotation, and analysis of corpora will lead to increased opportunities for sociolinguistic engagement with corpora. This is especially true for research investigating aspects of language and social structure (i.e. work in the first and second waves), though I believe it is still the case for work that is less interested in large-scale quantitative study. (KENDALL, 2011, p.371).

A importância desta questão está no fato de que o desenvolvimento e o compartilhamento de corpora atendem a um dos requisitos básicos do método científico, a replicabilidade. Segundo Kendall (2011, p.371), " [...] By working from a shared pool of data, researchers are best able to collectively develop agreed upon knowledge about language. This, I believe, is a major benefit of corpusbased work". Embora tenha se tornado mais comum, o compartilhamento de dados ainda não é prática corrente entre os pesquisadores da área da sociolinguística. Kendall identifica duas razões principais. A primeira é que o levantamento de corpora é um trabalho árduo, que nem sempre é reconhecido; portanto, faz sentido que os grupos que trabalharam no seu levantamento queiram limitar o acesso aos dados enquanto estão trabalhando em suas análises. A outra razão diz respeito ao direito à privacidade dos informantes. As coletas foram feitas, via de regra, com a autorização do informante de que os dados fossem utilizados em pesquisas com um determinado fim. A publicização dos dados nem sempre resguarda a garantia dada ao informante. Além disso, em entrevistas sociolinguísticas, frequentemente surgem temas privados do informante que este possivelmente não queira tornar públicos. Assim, a publicização dependeria de se poder recontatar todos os informantes e de se obter deles a autorização de compartilhamento. Como esse é um problema comum a entrevistas sociolinguísticas, é importante que se divulguem e se discutam protocolos de anonimização, como o que foi desenvolvido pelo Laboratório MUSL (Memorial University Sociolinguistic Laboratory) (CHILDS; VAN HERK; THORBURN, 2011).

O Banco VARSUL tem se ocupado com essas questões ao desenvolver o Projeto Amostra Digital, no qual entrevistas de informantes das três capitais, Porto Alegre, Florianópolis e Curitiba, são disponibilizadas a um público mais 
amplo ${ }^{11}$. Até o momento, a solução encontrada tem sido a de disponibilizar um conjunto de trechos das entrevistas das capitais Porto Alegre, Florianópolis e Curitiba, de forma a que pesquisadores de diversas áreas tenham uma amostra do material registrado no Banco. Para a escolha dos trechos disponibilizados, buscaram-se aquelas passagens em que o entrevistado discorre livremente, com o mínimo de intervenção do entrevistador. Mas também buscou-se privilegiar a escolha de passagens que não identificassem o informante. $O$ conjunto completo das entrevistas somente está disponível aos pesquisadores associados ao Projeto.

\section{Entrevista sociolinguística versus outros tipos de coleta}

Corpora de língua falada espontânea, coletados sistematicamente, têm uma série de vantagens em relação a outros tipos de levantamento. Segundo Ernestus e Baayen (2011, p.377):

[... s speech corpora are substantially broadening the empirical scope of phonological research. Corpora show that many well-established basic facts that constitute a kind of canon feeding both phonological theory and psycholinguistic theories involve substantial simplifications that do not do justice to the variability and the range of phenomena that characterize actual speech.

Em fonologia e fonética, análises de fala de laboratório são muito comuns e, muitas vezes, são a única forma disponível para se obter uma análise segura e confiável. No entanto, não deixam de ter desvantagens. As quantidades de dados coletados tendem a ser pequenas e normalmente não podem ser reutilizadas para fins diferentes. Além disso, estilos de fala eliciados em contexto de experimentos tendem a ser formais e não espontâneos, e materiais são apresentados de forma isolada ou em contextos pequenos, muitas vezes artificiais.

Em comparação com a fala de laboratório, obtida em resposta a instruções específicas, a fala casual apresenta enorme variabilidade na realização, refletindo não somente a filiação do falante a uma determinada comunidade linguística mas também padrões prosódicos que transmitem a estrutura de informação e o contexto pragmático de um enunciado, condições que nem sempre estão disponíveis na fala eliciada. Na visão de Ernestus e Baayen (2011), corpora de língua falada são importantes complementos para as análises experimentais.

Os autores citam como característica dos corpora de língua falada a revelação de que determinados processos fonético-fonológicos considerados de aplicação

\footnotetext{
Disponível em: <www.varsul.org.br>.
} 
categórica são, na verdade, de aplicação opcional, alguns dos quais com taxas de aplicação menores do que 50\%. Um exemplo apresentado refere-se ao processo de assimilação regressiva de vozeamento do holandês, considerado de aplicação categórica em muitas análises fonológicas; no entanto, um levantamento em corpus de língua falada mostrou que somente em $43 \%$ das ocorrências analisadas houve aplicação do vozeamento, contrariando os 100\% esperados. Outro aspecto que os corpora de língua falada revelam são os complexos padrões de redução de formas linguísticas. Segundo Ernestus e Baayen (2011), estas reduções não parecem ter caráter puramente fonético, já que os padrões de redução parecem estar sujeitos a uma variedade de condições intrinsecamente fonológicas. Os autores mencionam como exemplo o fato de que um elevado grau de redução é observado apenas para palavras que não portam acento sentencial e que se encontram em posição medial de enunciado, evidenciando que o padrão de redução está sujeito às mesmas condições de estrutura prosódica de processos de ordem fonológica.

A vantagem de corpora já coletados é economia de tempo e de recursos e também o acesso a um Banco de dados muito maior do que um único pesquisador individual poderia construir. Além disso, existe a possibilidade de tomar como base outros trabalhos que já tenham sido feitos usando o mesmo corpus, ou utilizando os resultados anteriores como referência para testar novos métodos de pesquisa. No entanto, para que uma coleção de arquivos de fala possa transcender os objetivos das pesquisas iniciais, que levaram à sua coleta, é preciso que os dados possam ser localizados através de transcrições, sendo o tipo de transcrição mais comum a transcrição ortográfica simples, que serve à função de fornecer pistas para acessar as formas a serem analisadas nos arquivos de voz.

No caso do Banco VARSUL, o corpus principal está totalmente transcrito, e cada transcrição é acompanhada de um arquivo com informações de características sociais dos falantes, incluindo idade, sexo, escolaridade, residência, tipo de trabalho que realiza, entre outros. Além disso, uma transcrição fonológica ampla está sendo desenvolvida com a ajuda de reconhecimento automático de fala para os trechos de fala disponibilizados no site da Amostra Digital. Este tipo de levantamento poderá ser útil, em pesquisas futuras, para a identificação de padrões de redução, medidas de taxa de elocução e de outras características da fala conectada e para a realização de uma mesma palavra ou locução em diferentes contextos prosódicos.

\section{O Banco de Dados VARSUL}

Os dados de língua falada do Projeto VARSUL foram coletados em situações espontâneas e, em certa medida, formam um corpus em larga-escala, por abrangerem amostras de diferentes regiões de um certo espaço geográfico e por contemplarem indivíduos de diferentes estratificações socioculturais. Desde o 
seu início, o Projeto era interdisciplinar, o que, em nosso entender, trouxe uma série de vantagens ao grupo.

O Banco de dados VARSUL reúne um grupo de professores pesquisadores ligados a três universidades da região sul do Brasil: Universidade Federal do Rio Grande do Sul (UFRGS), Universidade Federal de Santa Catarina (UFSC), Universidade Federal do Paraná (UFPR) e Pontifícia Universidade Católica do Rio Grande do Sul (PUCRS). Iniciou-se em 1990, com objetivo geral de oferecer subsídios para a descrição do português falado no País (BISOL; MENON; TASCA, 2008). Os dados estão disponíveis para pesquisas da comunidade acadêmica em geral, de acordo com regras estabelecidas pelo Projeto.

O Banco de dados dispõe de fichas sociais digitalizadas, contendo algumas informações sobre os entrevistados como estado civil, quantidade de filhos, renda familiar, religião, etc. As entrevistas foram realizadas em forma de diálogo entre duas pessoas, em estilo não controlado, tendo como tema principal a vida na cidade. Nas entrevistas, buscou-se obter narrativas sobre assuntos que fossem, ao mesmo tempo, de interesse do entrevistado e que pudessem ter pontos em comum com os relatos de outros informantes, como histórias que os pais contavam, um momento de raiva/alegria, etc. Busca-se, assim, captar, tanto quanto possível, a fala vernacular.

O material gravado foi transcrito segundo um sistema de transcrição próprio do Projeto, constituído por três linhas, para se possibilitar o acesso a diferentes informações e pesquisas em diferentes níveis linguísticos. Na primeira linha, é registrada, em forma ortográfica, a sintaxe real da fala dos informantes com interrupções e hesitações. Na segunda linha, registram-se aspectos fonéticos variáveis e as pausas. Na terceira linha, apresentam-se informações sobre a ênfase, mudança de velocidade de fala e uma classificação morfossintática dos itens lexicais. O roteiro de transcrição bem como os códigos específicos de cada linha estão disponíveis no Manual do Usuário do Projeto².

Essa forma de transcrição possibilitava, já na época de constituição do Banco, pesquisas de busca de palavras ou de sequência de palavras, assim como a sequência de caracteres da primeira linha ou de códigos usados nas linhas dois e três. Para auxiliar nesse sentido, foi criado um programa especial para o Projeto, denominado de Interpretador, que possibilita pesquisas lexicais, morfológicas e morfossintáticas, além das fonológicas nos arquivos de transcrição dos dados. Atualmente, este programa continua sendo usado, mas sua aplicabilidade é restrita à localização das ocorrências pretendidas e não permite contagens de ocorrências ou outros levantamentos mais sofisticados. Além disso, tendo sido concebido ainda na pré-história da linguagem computacional, por diversas razões, não pôde ser atualizado; em função disso, apesar de sua utilidade, acaba tendo um emprego limitado. Entretanto, novas ferramentas de busca desenvolvidas pela

Knies; Costa (1996). Ver também Menon; Fagundes; Loregian-Penkal (2009). 
linguística de corpus podem ser adaptadas ao emprego do Banco, o que deve se constituir em um dos desenvolvimentos subsequentes do Projeto VARSUL. Os dados de fala e suas transcrições estão disponíveis nas quatro sedes do Projeto³.

As amostras foram coletadas de 1988 a 1996 e são constituídas por dados de fala de indivíduos pertencentes a cidades étnico e/ou culturalmente representativas de cada Estado. Foram coletadas, seguindo a metodologia laboviana, 24 entrevistas, 96 por Estado, formando um total de 288, cada uma delas com duração aproximada de 60 minutos. Os indivíduos da amostra estão distribuídos por sexo, escolaridade e idade. A escolaridade é controlada por três graus de instrução, cuja nomenclatura antiga, primário, ginásio e $2^{\circ}$ grau, assim como sua estratificação, é substituída, nos dias atuais, geralmente, pela classificação por anos de estudo. Assim, os informantes estão divididos em até quatro, até oito e até onze anos de instrução. A idade, originalmente disposta em duas faixas, é, em alguns trabalhos, remodelada para três. Eis as cidades que compõem o Banco de dados básico:

(1) Cidades da Amostra Básica do Banco de Dados VARSUL (período de coleta- 1988 a 1994)

- Rio Grande do Sul: Porto Alegre, Flores da Cunha, Panambi e São Borja.

- Santa Catarina: Florianópolis, Blumenau, Chapecó e Lages.

- Paraná: Curitiba, Londrina, Irati e Pato Branco.

Outras cidades e localidades foram incorporadas ao longo dos anos no Banco VARSUL, como contribuições de trabalhos de mestrandos e doutorandos, desenvolvidos na linha laboviana. Há atualmente a incorporação de entrevistas com dados de fala, resultantes de teses de doutorado:

(2) Amostras Incorporadas ao Banco VARSUL, resultantes de Teses

\section{Rio Grande do Sul:}

a) amostra Bisol (1981): cidades de Taquara, Monte Bérico (distrito de Monte Bérico), Santana de Livramento, Porto Alegre ${ }^{4}$.

b) amostra Amaral (2000): cidade de São José do Norte ${ }^{5}$.

3 Informações socioculturais breves de cada cidade, bem como pequenos trechos ilustrativos de fala de cada lugar, podem ser obtidos pelo site <www.varsul.org.br>.

4 A amostra Bisol (1981) segue os preceitos da amostra básica do VARSUL com a mesma distribuição de informantes em sexo, escolaridade e idade. Foi coletada em 1978, pela própria autora, para fins de trabalho de doutorado. Abrange vinte e quatro entrevistas de cada cidade. Os dados encontram-se armazenados na PUCRS, disponíveis em fitas cassetes e em transcrições.

5 A amostra Amaral (2002) compreende 40 entrevistas coletadas na zona rural do município, em 1997, para fins de trabalho de tese de doutorado. Os informantes estão distribuídos por sexo, escolaridade (de 0 a 4 anos e até 4 anos). 


\section{Santa Catarina:}

amostra Brescancini (2002): cidade de Florianópolis e distritos de Ribeirão da thha e Barra da Lagoa 6 .

Além de coletas de dados de teses, cedidas para o VARSUL, há o armazenamento na sede VARSUL/UFRGS de alguns dados de Porto Alegre do Projeto Norma Urbana Culta (NURC). Esses dados, coletados entre 1971 e 1978, segundo Menon (2008, p.337), encontram-se em rolos de fitas magnéticas, o que dificulta o acesso de pesquisadores. Também há o acréscimo de novas amostras, contemplando novas regiões, escolaridade, faixas etárias, como a fala de jovens de Porto Alegre (até 25 anos), de universitários e de quinze informantes recontatados do Projeto NURC, em 1999. Atualmente, a maior parte desses dados não se encontra disponível em meio eletrônico e não tem transcrição, mas projeta-se essa tarefa. Há também a incorporação dos dados de Flores da Cunha (RS) do Banco BDSer (Banco de Dados de Fala da Serra Gaúcha), cedidos pela Universidade de Caxias do Sul.

Nesses últimos anos, foram realizadas dezenas de trabalhos com os dados do Banco VARSUL, com divulgação nacional e internacional. Artigos, capítulos de livros, dissertações e teses trataram de expor diferentes estudos sobre variação e mudança linguística nas áreas de fonologia, morfologia, sintaxe, léxico, pragmática e discurso, em relação à fala do Sul do Brasil.

Os objetivos a que se propôs desde seu surgimento (BISOL; MENON; TASCA, 2008) foram e estão sendo, sem dúvida, cumpridos. Retomando-os, aqui, são os que seguem: oferecer subsídios para a descrição do português no País; dar condições para teste e desenvolvimento de teorias linguísticas; fornecer condições para formação de novos pesquisadores e subsídios para programas educacionais, promovendo o conhecimento e o respeito às variedades linguísticas.

No que diz respeito à descrição do português, estudos na área de Fonologia têm se encarregado de abranger diversos processos e contextos linguísticos, como forma de dar visibilidade, em termos gerais, ao panorama de fenômenos variáveis presentes na fala da região. Dezenas de trabalhos expõem, por meio de dados do Projeto VARSUL, resultados valiosos para a compreensão da língua portuguesa falada no Brasil, contemplando a teoria da Fonologia e a proposta da Sociolinguística Quantitativa.

A amostra Brescancini (2002) compõe-se por 100 informantes, sendo 48 referentes à região urbana do município e 52 às regiões interioranas. 


\section{Pesquisas com o Banco VARSUL na Área de Fonologia}

A variação fonológica no sul do País tem sido persistentemente pesquisada no Banco VARSUL por um grupo de pesquisadores encabeçado por Leda Bisol. Com o objetivo de traçar um panorama dos trabalhos realizados pelo grupo de pesquisadores, ligados a diferentes universidades do Rio Grande do Sul, listamos a seguir os processos fonológicos examinados.?

(3) Fenômenos Fonológicos Examinados com o Banco VARSUL

a) alçamento de vogais pretônicas, como as realizações m[i]nino, melh[u]ria, p[i]queno, por exemplo;

b) elevação de vogais postônicas final e não final, como em bol[u], lev[i], núm[i]ro, côm[u]do;

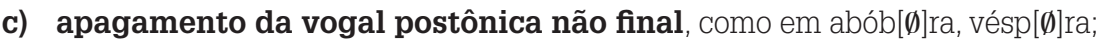

d) redução de ditongos nasais átonos, como em home[ø], órg[u];

e) epêntese vocálica em grupos consonantais, como em p[i]neu, ad[e]vogado;

f) fenômenos de juntura vocabular, como degeminação (menin[a]amada), elisão (verd[a]marelo) e ditongação (verd[ja]marelo);

g) variação de líquidas laterais, como em sa[w]gado (salgado), mu[l]e (mulher);

h) variação de vibrantes prevocálicas (rato), intervocálicas (carro) e pós-vocálicas (mar, carta);

i) variação de oclusivas dentais /t/ e /d/ diante de [i], como em palavras como tia e dia;

j) variação de /s/ posvocálico em palavras como paz e peste, por exemplo;

k) monotongação de ditongos decrescentes, como em fe[j]ra (feira), co[j]ro (couro);

l) ditongação em contextos seguidos por sibilantes, como em fa[j]z (faz) e de[j]z (dez);

m) haplologia sintática em sequência de sílabas com /t/ e /d/ subjacentes: resto do ano>res do ano; qualidade de vida> qualida de vida.

Em relação à abrangência dos fenômenos fonológicos estudados, as descrições contemplam amostras de quase todas as cidades do Banco. De fato, a região sul pode, por meio das amostras do Banco, oferecer conhecimento sobre o comportamento variável de diversos processos fonológicos. A questão que se

Uma descrição mais abrangente desses estudos pode ser encontrada em Bisol e Brescancini (2002), Bisol e Collischonn (2009) e Revista de Letras (2005). 
coloca, depois de tantos anos de investigação, é: o que os dados mostram sobre a fala do sul do País? É possível se fazer inferências sobre um levantamento exaustivo de casos em que um elemento variável poderia ter ocorrido, mas que não ocorreu? Labov (2008) defende que os dados numéricos permitem identificar implicações e fazer inferências, atendendo-se ao Princípio de Explicabilidade.

A importância dos dados é reconhecida para estudo teórico de língua. Por isso, um dos objetivos básicos da Sociolinguística Quantitativa é produzir resultados que podem ser generalizados no que diz respeito ao comportamento de uma extensa população. Para Bailey e Tillery (2004), generalização implica em veracidade, que pode ser obtida quando há resultados semelhantes em observações repetidas do mesmo fenômeno, e em intersubjetividade, quando há o mesmo resultado para um mesmo fenômeno observado por diferentes pesquisadores.

No caso do Banco Varsul, há pesquisas que podem ser comparadas por abrangerem mesmo fenômeno linguístico, na tentativa de se generalizar resultados. As regras variáveis examinadas distribuem-se por diferentes pesquisas, como pode se ver no quadro 1 , sobre os trabalhos realizados em diferentes coletas, a respeito de determinados fenômenos fonológicos.

\section{Quadro 1 - Pesquisas comparáveis com Dados do VARSUL por abrangerem o mesmo fenômeno}

- Harmonia Vocálica: Bisol (1981), Battisti (1993), Schwindt (1995, 2002), Casagrande (2004), Silva (2012).

- Alçamento de /e/ e de /o/ Postônico: Schmitt (1987), Vieira (1994, 2002, 2009), Roveda (1998), Carniato (2000).

- /r/ Posvocálico: Monaretto (1992, 1997, 2000, 2002, 2009), Monguilhott (1997), Gregis (2003), Pimentel (2003), Silveira (2010).

- /l/ Posvocálico: Quednau (1993), Tasca (1999, 2002), Espiga (2001), Collischonn e Costa (2005), Costa (2003), Collischonn e Quednau (2009).

- Palatalização das Oclusivas Dentais /t/ e /d/ diante de [i]: Bisol (1991), Almeida (2000), Kamianecky (2003), Pires (2007), Zamboni (2006), Battisti e Guzzo (2009).

Fonte: Elaboração própria.

O Banco VARSUL compreende amostras coletadas, em termos gerais, em três períodos, que deram origem a diferentes pesquisas, como pode ser visto pela ilustração do gráfico 1. O ano de 1978 representa a amostra de Bisol (1981); o de 1998, o de coleta da amostra base do VARSUL; e o de 1999, o de coleta de universitários e de recontato do NURC. 


\section{Gráfico 1 - Distribuição de pesquisas por períodos de coletas de amostras do VARSUL}

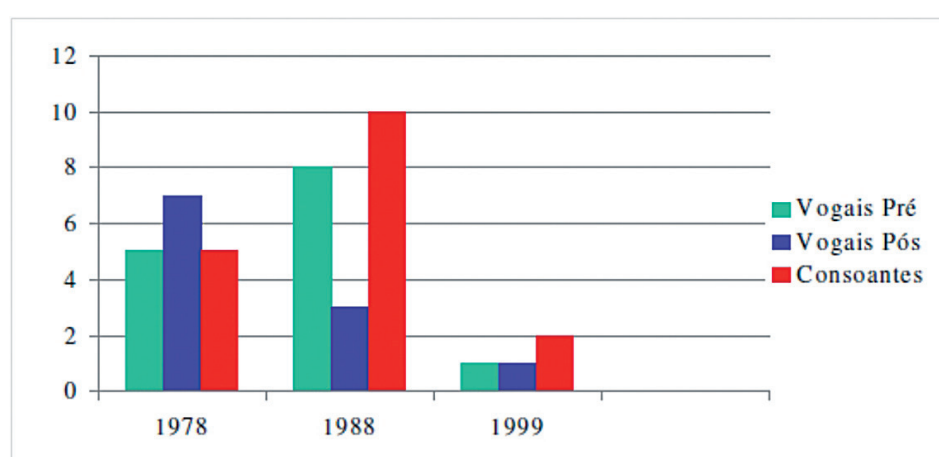

Fonte: Elaboração própria.

Segundo Bailey e Tillery (2004), para certificar a generalização de resultados, é preciso verificar a origem dos dados (época de coleta); a constituição da amostra (comunidades e estratificação) e os procedimentos analíticos utilizados na pesquisa (levantamento de dados, delimitação de variáveis dependentes e independentes, amálgamas, cruzamentos, etc.). Descrições, algumas vezes, podem ser divergentes em termos de resultados por questões metodológicas utilizadas nas pesquisas. As características sociais do entrevistador, por exemplo, ou a presença de outra pessoa na entrevista, podem provocar efeitos nos entrevistados que afetam os dados. A seleção da amostra e os meios de sua estratificação podem também acarretar diferenças de resultados, assim como as estratégias analíticas utilizadas em trabalhos sobre um mesmo fenômeno.

Em relação às amostras utilizadas, apesar de as localidades serem distintas, é possível de se testar a regularidade e intersubjetividade, fundamentais, segundo Bailey e Tillery (2004), para a generalização de dados. ${ }^{8}$ A regra variável de apagamento da vibrante pós-vocálica, por exemplo, ao ser examinada por diferentes pesquisadores e localidades do Banco VARSUL, e por estratégias analíticas, por vezes, também divergentes, pode ser generalizada por ter sido apontada, unanimemente em todos trabalhos, por ocorrer em final de verbos no infinitivo. O papel das variáveis sociais não é consenso entre as pesquisas, mas indica, preliminarmente, os homens como líderes do processo.

Outros fenômenos fonológicos podem ser verificados em termos de generalização de resultados. Há muitas pesquisas já realizadas que podem atestar a veracidade dos dados do Banco VARSUL. Eis, pois, uma preciosidade imensa para a descrição da fala do português brasileiro.

8 Propostas de exercícios comparativos entre pesquisas sobre mesmos fenômenos podem ser vistas em trabalhos sobre a discussão de efeitos de metodologia em regras variáveis com dados do VARSUL, em Brescancini (2011) e Monaretto (2008). 


\section{Considerações Finais}

Neste artigo, mostramos inicialmente que as características do Banco VARSUL o inscrevem na primeira onda dos estudos sociolinguísticos, conforme a divisão proposta em Eckert (2012), e procuramos mostrar que a sua relevância não se esgota em pesquisas de cunho variacionista. Mostramos que corpora de língua falada em larga escala são, potencialmente, fonte útil de observação de dados de língua também para pesquisadores de outras áreas, especialmente das áreas de linguística de corpus e da geolinguística. Enfatizamos também a importância de dados de fala espontânea para análises fonológicas na atualidade, destacando algumas de suas vantagens, que podem complementar estudos feitos na base de fala de laboratório. Também abordamos as dificuldades inerentes à constituição e transcrição de Bancos de dados linguísticos de larga escala. O Banco de dados VARSUL é reapresentado, com exposição das amostras disponíveis para pesquisas em diferentes áreas, assim como um retrato dos trabalhos desenvolvidos na área de variação fonológica. Mostramos também que os levantamentos permitem atualmente elaborar pesquisas de cunho metametodológico, no sentido de testar a veracidade dos resultados, na linha do que propõem Bailey e Tillery (2004).

COLLISCHONN, G.; MONARETTO, V. de O. Database VARSUL: relevance of its features and scope of its results. Alfa, São Paulo, v.56, n.3, p.XX-XX, 2012.

- ABSTRACT: The VARSUL Database (Urban Language Variation in the South of the Country) assembles speech data from social and culturally significant locations of the three southern states of Brazil. This article presents some considerations on the use, -both in the field of language variation and in several other fields of research, especially as regards to phonological phenomena - of data collections gathered according to the Labovian approach. The importance and advantages obtained by corpora analyses of spontaneous spoken language are addressed. We also discuss the possibilities that collections of sociolinguistic interviews provide for interface with other areas of research. Some features of the constitution of the VARSUL Database are presented, such as data collection methodology, criteria for informants selection, transcription protocols, as well as search devices developed for this Database. Finally, a survey of researches conducted on these data involving phonetic-phonological variables is presented to illustrate the scope of phenomena that have been studied and to show the possibility of generalization of results.

- KEYWORDS: VARSUL. Speech Database. Phonological Variation. 


\section{REFERÊNCIAS}

ALMEIDA, M.A.B. de. A variação das oclusivas dentais na comunidade bilíngüe de Flores da Cunha: uma análise quantitativa. 2001. 106f. Dissertação (Mestrado em Lingüística e Letras) - Pontifícia Universidade Católica do Rio Grande do Sul, Porto Alegre, 2001.

AMARAL, M. P. As proparoxítonas: teoria e variação. 2000. 222f. Tese (Doutorado em Lingüística Aplicada) - Pontifícia Universidade Católica do Rio Grande do Sul, Porto Alegre, 2000.

BAILEY, G.; TILLERY, J. Some sources of divergent data in sociolinguistics. In: FOUGHT, C. Sociolinguistic variation: critical reflections. New York: Oxford University, 2004. p.11-30.

BATTISTI, E. Elevação das Vogais Médias Pretônicas em Sílaba Inicial de Vocábulo na Fala Gaúcha. Porto Alegre. 1993. 125f. Dissertação (Mestrado em Letras) - Pontifícia Universidade Católica do Rio Grande do Sul, Porto Alegre, 1993.

BATTISTI, E. ; GUZZO, N. B. Palatalização das oclusivas alveolares: o caso de Chapecó (SC). In: BISOL, Leda; COLLISCHONN, Gisela. (Org.). Português do sul do Brasil: variação fonológica. Porto Alegre: Ed. da PUCRS, 2009. v.1. p.114-149.

BISOL, L. Palatalization and its variable restriction. International Journal of Sociology of Language, New York, n.89, p.107-124, 1991.

Harmonia vocálica: uma regra variável. 1981. 332f. Tese (Doutorado em Lingüística) - Universidade Federal do Rio de Janeiro, Rio de Janeiro, 1981.

BISOL, L.; BRESCANCINI, C. (Org.). Fonologia e variação: recortes do português brasileiro. Porto Alegre: Ed. da PUCRS, 2002.

BISOL, L.; COLLisCHONN, G. (Org.). Português do sul do Brasil: variação fonológica. Porto Alegre: Ed. da PUCRS, 2009. Disponível em: <http://www.pucrs. br/edipucrs/portuguesdosuldobrasil.pdf>. Acesso em: 25 set. 2012.

BISOL, L.; MENON, O. P.; TASCA, M. VARSUL: um banco de dados. In:VOTRE, S.; RONCARATI, C. (Org.). Anthony Naro e a linguística no Brasil: uma abordagem acadêmica. Rio de Janeiro: Letras, 2008.

BRANDÃO, S. F. Sociolinguística e geolinguística: uma perspectiva histórica. In: BARRETTO, M.; SALGADO, A. C. (Org.). Sociolinguística no Brasil: uma contribuição de estudos sobre línguas/contato. Rio de Janeiro: 7 Letras, 2009. p.88-92.

BRESCANCINI, C. A elevação da vogal postônica final no Rio Grande do Sul: uma leitura à luz de Bailey e Tillery. In: COLLISCHONN, G.; BATTISTI, E. (Org.) Língua e linguagem: perspectivas de investigação. Pelotas: EDUCAT, 2011. p.227-251. 
BRESCANCINI, C. A fricativa palato-alveolar e sua complexidade: uma regra variável. 2002. 362f. Tese (Doutorado em Letras) - Pontifícia Universidade Católica do Rio Grande do Sul, Porto Alegre, 2002.

BRESCANCINI, C.; MONARETTO, V. Os róticos no sul do Brasil: panorama e generalizações. SIGNUM, Londrina, v.11, n.2, p.51-66, dez. 2008.

CALLOU, D. Quando dialetologia e a sociolinguística se encontram. Estudos Linguísticos e Literários, Salvador, n.41, p.29-48, jan./jun. 2010.

CARNIATO, M. C. A neutralização das vogais postônicas finais na comunidade de Santa Vitória do Palmar. 2000. 111p. Dissertação (Mestrado em Letras) Universidade

Católica de Pelotas, Pelotas, 2000.

CASAGRANDE, G. P. B. Harmonização vocálica: análise variacionista em tempo real. 2004. 171f. Dissertação (Mestrado em Letras) - Pontifícia Universidade Católica do Rio Grande do Sul, Porto Alegre, 2004.

CHILDS, B.; HERK, G.; THORBURN, J. Safe harbour: ethics and accessibility in sociolinguistic corpus building. Corpus Linguistics and Linguistic Theory, Ypsilanti, v.7, n.1, p.163-180, maio 2011.

COETZEE, A. W.; PATER, J. The place of variation in phonological theory. In: GOLDSMITH, J.; RIGGLE, J.; YU, A. C. L. (Org.). The handbook of phonological theory. 2. ed. Malden:Wiley-Blackwell, 2011. p.401-434.

COLLISCHONN, G.; COSTA, C. F. Ressilabação da lateral pós-vocálica final e sua limitação prosódica. Letras de Hoje, Porto Alegre, v.40, n.3, p.7-38, 2005.

COLLISCHONN, G.; QUEDNAU, L. As laterais variáveis da Região Sul. In: BISOL, L.; COLLiSCHONN, G. (Org.). Português do sul do Brasil:variação fonológica. Porto Alegre: Ed. da PUCRS, 2009. p.154-176.

COSTA, C. F. Fonologia lexical e controvérsia neogramática: análise das regras de monotongação de /ow/ e vocalização de // no PB. 2003. 129f. Dissertação (Mestrado em Letras) - Universidade Federal do Rio Grande do Sul, Porto Alegre, 2003.

DURAND, J. On the scope of linguistics: data, intuitions, corpora. In: KAWAGUCHI, Y.; MINEGISHI, M.; DURAND, J. (Ed.). Corpus analysis and variation in linguistics. Amsterdam: John Benjamins, 2009. p.25-52.

ECKERT, P. Three waves of variation study: the emergence of meaning in the study of sociolinguistic variation. Annual Review of Anthropology, Palo Alto, v.41, p.87-100, 2012. Disponível em: <http://www.stanford.edu/ eckert/PDF/ ThreeWaves.pdf>. Acesso em: 30 mar. 2012. 
ERNESTUS, M.; BAAYEN, H. Corpora and exemplars in phonology. In: GOLDSMITH, J.; RIGGLE, J.; YU, A. C. L. (Org.). The handbook of phonological theory. 2. ed. Malden:Wiley-Blackwell, 2011. p.374-400.

ESPIGA, J. O português dos campos neutrais:um estudo sociolingüístico da lateral posvocálica nos dialetos fronteiriços de Chuí e Santa Vitória do Palmar. 2001. $154 f$. Tese (Doutorado em Lingüística e Letras) - Pontifícia Universidade Católica do Rio Grande do Sul, Porto Alegre, 2001.

GOLDSMITH, J.; RIGGLE, J.; YU, A. C. L. (Org.). The handbook of phonological theory. 2. ed. Malden:Wiley-Blackwell, 2011. p.401-434.

GREGIS, H. O apagamento da vibrante pós-vocálica em Porto Alegre. 2002. $111 \mathrm{f}$.

Dissertação (Mestrado em Letras) - Universidade Federal do Rio Grande do Sul, Porto Alegre, 2002.

HINSKENS, F.; VAN HOUT, R.; WETZELS, L. Um balanço de dados e teoria no estudo da variação e da mudança fonológica. Tradução de Marisa Porto do Amaral. Letras de Hoje, Porto Alegre, v.35, n.1, p.7-46, mar. 2000.

KAMIANECKY. F. Palatalização das oclusivas dentais nas comunidades de Porto Alegre e Florianópolis: uma análise quantitativa. 2003. 114f. Dissertação (Mestrado em Letras) - Pontifícia Universidade Católica do Rio Grande do Sul, Porto Alegre, 2003.

KENDALL, T. Corpora from a sociolinguistic perspective. RBLA, Belo Horizonte, v.11, n.2, p.361-389, 2011.

KNIES, C.; COSTA, I. Manual do usuário - Banco de Dados linguísticos VARSUL. 1996. Disponível em: <http://www.varsul.org.br/?modulo=secao\&id=1 $>$. Acesso em: 30 mar. 2012.

LABOV, W. Quantitative reasoning in linguistics. Linguistics 563, Philadelphia, p.24, jan. 2008.

The social stratification of English in New York City. Washington: Center of Applied Linguistics, 1966.

MENON, O. P. Uniformitarismo ou transmissão oral. In:VOTRE, S.; RONCARATI, C. (Org.). Anthony Naro e a linguística no Brasil: uma abordagem acadêmica. Rio de Janeiro: Letras, 2008. p.337-351.

MENON, O. P.; FAGUNDES, E. D.; LOREGIAN-PENKAL, L. The Varsul Database. Linguistik online, Unitobler, v.38, n.2, p.2, 2009. Disponível em: <http://www. linguistik-online.de/38_09/menonEtAl.html>. Acesso em: 25 set. 2011.

MONARETTO, V. N. O. Descrição da vibrante no português do sul do Brasil. In: BISOL, L.; COLLISCHONN, G. (Org.). Português do sul do Brasil: variação 
fonológica. Português do sul do Brasil: variação fonológica. Porto Alegre: Ed. da PUCRS, 2009. v.1. p.141-151.

. A vibrante pós-vocálica em Porto Alegre. In: BISOL, L.;

BRESCANCINI, C. Fonologia e variação: recortes do português brasileiro. Porto Alegre: Ed. da PUCRS, 2002. p.253-268.

. O apagamento da vibrante pós-vocálica nas capitais da

fala do sul do Brasil. Letras de Hoje, Porto Alegre, v.35, n.1, p.275-284, mar. 2000.

Um reestudo da vibrante: análise variacionista e fonológica. 1997. $213 f$. Tese (Doutorado em Lingüística e Letras) - Pontifícia Universidade Católica do Rio Grande do Sul, Porto Alegre, 1997.

A vibrante: representação e análise sociolingüística. 1992. $104 f$. Dissertação (Mestrado em Letras) - Universidade Federal do Rio Grande do Sul, Porto Alegre, 1992.

MONGUILHOTT, I. O. S. A vibrante em final de palavra na fala de Santa

Catarina. In: ENCONTRO DO CÍRCULO DE ESTUDOS LINGUÍSTICOS DO SUL, 2., 1997,

Florianópolis. Anais... Florianópolis: UFSC: Celsul, 1997. CD-ROM.

MOTA, J. A. Sociolinguística e sociolinguística no Brasil: caminhos e encontros. In: BARRETTO, M.; SALGADO, A. C. (Org.). Sociolinguística no Brasil: uma contribuição de estudos sobre línguas/contato. Rio de Janeiro: 7 Letras, 2009. p.93-98.

PIMENTEL, R. A variação lingüística do fonema /r/ na posição pós-vocálica em falantes da cidade de Porto Alegre. 2003. 105f. Dissertação (Mestrado em Letras) - Pontifícia Universidade Católica do Rio Grande do Sul, Porto Alegre, 2003.

PIRES, L. B. A palatalização das oclusivas dentais em São Borja. Revista Virtual de Estudos da Linguagem - ReVEL. Edição especial n.1, p.1-23, 2007.

QUEDNAU, L. R. A lateral pós-vocálica no português gaúcho: análise variacionista e representação não-linear. 1993. 150f. Dissertação (Mestrado em Letras) Universidade Federal do Rio Grande do Sul, Porto Alegre, 1993.

REVISTA DE LETRAS. Porto Alegre: PUCRS, n.141, set. 2005.

ROVEDA, S. D. Elevação da vogal média átona final em comunidades bilingues: Português e Italiano. 1998. 87f. Dissertação (Mestrado em Lingüística e Letras) Pontifícia Universidade Católica do Rio Grande do Sul, Porto Alegre, 1988.

SCHMITT, C. J. Redução vocálica postônica e estrutura silábica. 1987. $139 f$. Dissertação (Mestrado em Letras) - Universidade Federal do Rio Grande do Sul, Porto Alegre, 1987. 
SCHWINDT, L. C. A regra variável de harmonização vocálica no RS. In: BISOL, Leda; BRESCANCINI, Claudia (Org.). Fonologia e variação:recortes do português brasileiro. Porto Alegre: Ed. da PUCRS, 2002. p.161-182.

. A harmonia vocálica nos dialetos do sul do país:uma análise variacionista. 1995. 76f. Dissertação (Mestrado em Letras) - Pontifícia Universidade Católica do Rio Grande do Sul, Porto Alegre, 1995.

SILVA, M. E. da. O alçamento das vogais médias pretônicas na fala de São José do Norte/RS: harmonia vocálica. 2012. 144f. Dissertação (Mestrado em Letras) Universidade Federal do Rio Grande do Sul, Porto Alegre, 2012.

SILVEIRA, G. da. O Apagamento da vibrante na Fala do Sul do Brasil: sob ótica da palavra. 2010. 129f. Dissertação (Mestrado em Letras) - Universidade Federal do Rio Grande do Sul, Porto Alegre, 2010.

TASCA, M. Variação e mudança no segmento lateral na coda silábica. In: BISOL, L.; BRESCANCINI, C. Fonologia e variação: recortes do português brasileiro. Porto Alegre: Ed. da PUCRS, 2002. p.269-302.

A lateral em coda silábica no sul do Brasil. 1999. 147f. Tese (Doutorado em Lingüística e Letras) - Pontifícia Universidade Católica do Rio Grande do Sul, Porto Alegre, 1999.

VIEIRA, M. J. B. As vogais médias átonas nas três capitais do sul do país. In: BISOL, L.; COLLISCHONN, G. (Org.). Português do sul do Brasil: variação fonológica. Português do Sul do Brasil: variação fonológica. Porto Alegre: Ed. da PUCRS, 2009. v.1. p.50-72.

As vogais médias postônicas: uma análise variacionista. In: BISOL, L.;

BRESCANCINI, C. (Orgs.). Fonologia e variação: recortes do português

Brasileiro. Porto Alegre: Ed. da PUCRS, 2002. p.127-159.

Neutralização das vogais médias postônicas. 1994. 139f. Dissertação (Mestrado em Lingüística e Letras) - Pontifícia Universidade Católica do Rio Grande do Sul, Porto Alegre, 1994.

ZAMBONI, A de P. A palatalização das oclusivas dentais. 2006. 152f. Dissertação (Mestrado em Letras) - Universidade Federal do Rio Grande do Sul, Porto Alegre, 2006.

Recebido em abril de 2012.

Aprovado em julho de 2012. 